\title{
Alumina-hydroxyapatite nanocomposites and their applications for the removal of phenolic compounds from water: A comparative study
}

\author{
Khadija Bouiahya*, A. Oulguidoum, Abdelaziz Laghzizil \\ Laboratoire de Chimie Appliquée des Matériaux, Faculté des Sciences, Université Mohammed V, Rabat \\ Morocco
}

\begin{abstract}
This study develops cost-effective adsorbents for the treatment of water contaminated with phenolic compounds, including Phenol $(\mathrm{Ph}), 2$-Chlorophenol (2-CPh), and 2-Nitrophenol (2-NPh). Therefore, AluminaHydroxyapatite composites were prepared from natural phosphate in the presence of $\mathrm{Al}^{3+}$ ions characterized by various techniques and then the supplementary active sites on their surface may make a better contribution to the phenols remediation. It was concluded that the specific surface area, surface charge and Al content were very suitable for the more adsorptive removal. Results show that the 2-chlorophenol is the more affinity versus hydroxyapatite and its formed composites compared to $2-\mathrm{NPh}$ and $\mathrm{Ph}$ in order $2-\mathrm{CPh}>2-\mathrm{NPh}>\mathrm{Ph}$.
\end{abstract}

\section{Introduction}

Phenolic compounds are well known for their carcinogenicity, high toxicity and unpleasant tests and odor in aqueous solutions [1]. Several treatment processes have been tried to remove phenol and its derivatives contained in industrial effluents [2-4]. Synthetic and natural adsorbents are widely described in the literature with huge retention capabilities [5-7]. Their effectiveness in removing these toxic species from water depends of large extent on the characteristics of the adsorbent and the experimental parameters of the adsorption process. Among these adsorbents, natural and synthetic apatites are considered as good water depollution agents [8-10]. The best performance of the phenols retention is related to their porosity, which allows them to better preserve of various organic and mineral elements. It is all the more interesting that the adsorbent is abundant and inexpensive. The adsorptive removal of various toxic organic molecules by alumina has been reported elsewhere $[6,11]$ and its association with other materials improves its activity [12, 13]. Therefore, its association with apatite conducts porous nanocomposites may be cost effective adsorbents for water treatment. For this purpose, $\mathrm{Al}_{2} \mathrm{O}_{3}$-Hydroxyapatite composites prepared by using a natural phosphate as calcium and phosphorus precursors were used for the removal of phenol $(\mathrm{Ph}), 2$-chlorophenol (2-CPh) and 2nitrophenol (2-NPh) from water.

\section{Experimental}

\subsection{Synthesis}

The pure hydroxyapatite (HAp) was prepared from dissolution/precipitation of natural phosphate from Bengurir region (Morocco) as described elsewhere [14], while the $\mathrm{Al}_{2} \mathrm{O}_{3}$ - $\mathrm{HAp}$ composites were prepared by the co-precipitation method in strong alkaline solutions [13].
In fact, the filtered solution resulting from the dissolution of the natural phosphate was mixed with $\mathrm{Al}^{3+}$ solution followed by neutralization treatment using concentrated ammonia (25\%) until $\mathrm{pH} 10$. The mixture was left to mature for 24 hours, then ultrasonically dispersed for $15 \mathrm{~min}$, filtered and washed several times with distilled water. Then the precipitate is re-dispersed in water, sonicated, washed and oven dried at $100^{\circ} \mathrm{C}$ overnight. The dried powders are then calcined at $800^{\circ} \mathrm{C}$ for 3 hours for structural investigations. The resulting samples were named as wAlHAp, where $\mathrm{w}$ is the weight ratio $\mathrm{Al}_{2} \mathrm{O}_{3}: \mathrm{HAp}(\mathrm{w}=5,10)$.

\subsection{Adsorption experiments}

The phenolic stock solution is prepared by dissolving 1.0 $\mathrm{g}$ of phenol, 2-chorophenol, and 2-nitrophenol in water. The adsorption tests of phenolic compounds on wAlHAp composites as a function of experimental parameters was carried out under static conditions using a multi-station magnetic stirrer. The kinetics of phenolic sorption on composites were carried out at initial concentration 20 $\mathrm{mg} / \mathrm{L}$ at desired $\mathrm{pH}$ with $2 \mathrm{~g} / \mathrm{L}$ as optimum adsorbent dose. When the adsorption reached equilibrium, the equilibrium concentration $\left(\mathrm{C}_{\mathrm{e}}\right)$ of $\mathrm{Ph}, 2-\mathrm{CPh}$, and $2-\mathrm{NPh}$ species was determined using UV-visible spectrophotometer after centrifugation. The values of maximum wavelength for phenol, 2-chlorophenol and 2nitrophenol were determined for the each system used in the present study. The instantaneous adsorption capacity $\left(\mathrm{q}_{\mathrm{t}}, \mathrm{mg} \cdot \mathrm{g}^{-1}\right)$ was calculated according to the following equation: $\mathrm{q}_{\mathrm{t}}=\left(\mathrm{C}_{0}-\mathrm{C}_{\mathrm{e}}\right) . \mathrm{V} / \mathrm{m}$, where $\mathrm{C}_{0}(\mathrm{mg} / \mathrm{L})$ is the initial concentration of solute, $\mathrm{C}_{\mathrm{e}}(\mathrm{mg} / \mathrm{L})$ is the equilibrium concentration, $\mathrm{V}(\mathrm{L})$ is the volume of solution, and $\mathrm{m}(\mathrm{g})$ is the weight of the adsorbent.

\footnotetext{
Corresponding author: author@e-mail.org
} 


\section{Results and discussion Results and discussion}

Structural and surface properties of the wAlHAP adsorbents were investigated. XRD patterns of dried HAp and 10AlHAp powders was matched to the pure apatite phase structure (Fig.1), demonstrating that $\mathrm{Al}^{3+}$ ions are either inserted into the apatite structure having a poor crystallinity, and/or giving amorphous $\mathrm{Al}_{2} \mathrm{O}_{3}$ oxide. After the samples were calcined at $800^{\circ} \mathrm{C}$, a separation alumina and apatite phases was done mainly for high $\mathrm{Al}$ content.

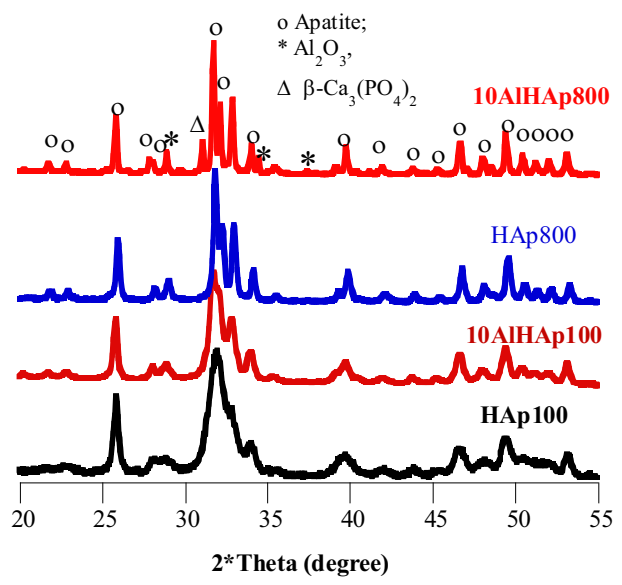

Figure 1: XRD patterns of the dried and calcined HAp and 10AlHAp powders.

Figure2 shows the SEM images viewing the surface texture and porosity of 10AlHAp compared to HAp, translated by holes and small openings at the surface reflecting the existence of pores, which is beneficial for the diffusion of phenolic species during the adsorption process. This has been proved by specific surface measurements by the BET method (Table 1).
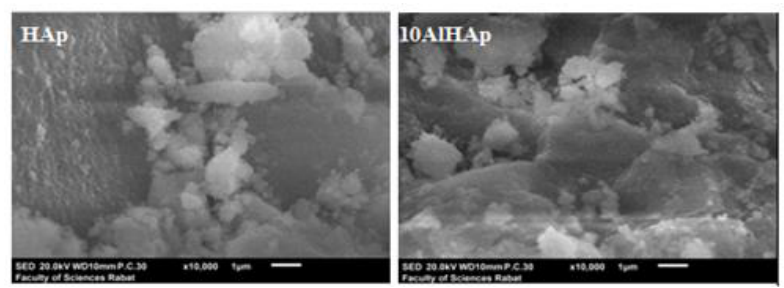

Figure 2: SEM images of pure hydroxyapatite and 10AlHAp composite dried at $100^{\circ} \mathrm{C}$.

Results clearly show that the addition of aluminum to the apatite structure clearly improves the porosity of which the greatest value of the specific surface area was found for 5AlHAp. A modification of the apatite surface by $\mathrm{Al}^{3+}$ ions was achieved by the creation of pores and the addition of positive charges on the surface of the composites formed. This leads us to discuss the effective role of the alumina phase on the retention of phenolic species in relation to the characteristics of the surfaces obtained from the elaborated composites. The effect of contact time between "pollutant-adsorbent" is of significant importance in the wastewater treatment by adsorption. Figure 3 illustrates the evolution of the adsorbed quantity as a function of time characterized by a strong adsorption of phenolic compounds from the first 10 minutes, followed by a slow process until equilibrium state. It is certainly related the number of active sites available on the adsorbent surface, which is much more important than the one left after saturation. The time required for the phenolic compounds to reach the equilibrium condition was rapid (10-20 $\mathrm{min})$ for $2-\mathrm{CPh}$, longer for phenol (60- $65 \mathrm{~min}$ ) and very long for 2-NPh (beyond $120 \mathrm{~min}$ ). At Equilibrium, the 5AlHAp and 10AlHAp retain more phenolic species than a pure HAp.

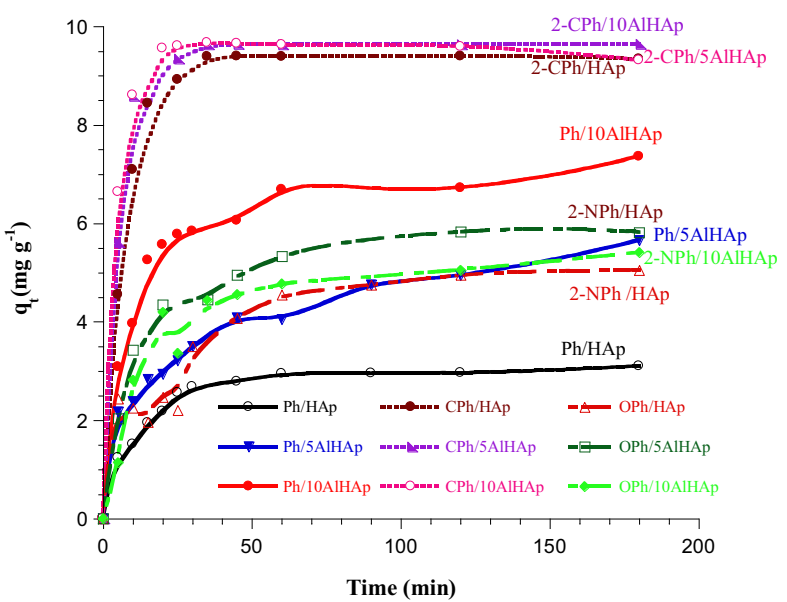

Figure 3. Effect of contact time for the adsorptive removal of phenol $(\mathrm{Ph}), 2$-chlorophenol, and 2nitrophenol on HAp, 5AlHAp and 101HAp dried at $100^{\circ} \mathrm{C}$.

The figure 4 shows the $\mathrm{pH}$ effect on the adsorption of $\mathrm{Ph}$ and $2-\mathrm{NPh}$ on HAp and 5AlHAp powders. It is found that the adsorption capacity is maximum at $\mathrm{pH}=5$ for phenol and $\mathrm{pH} 7$ for $2-\mathrm{NPh}$. Therefore, the negative charge of phenols is dominant on the surface of the adsorbent and thus a substantially high electrostatic attraction exists between the positive charges of the surface of the adsorbent and the negative charges of the phenolates formed, which favors the adsorption [15]. Outside these pHs, the dominant charge of the surface of the adsorbent is less accentuated which decreases the adsorption of phenolates carrying the same charge.

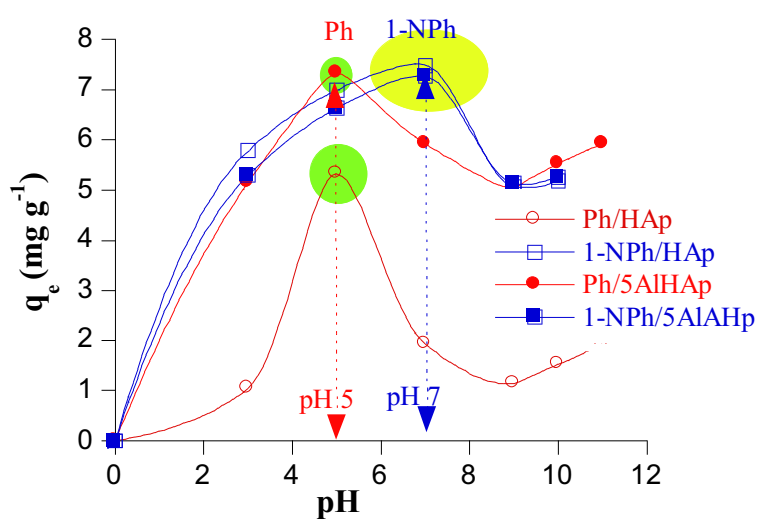

Figure 4. Variations of adsorption capacity of phenol and 2-nitrophenol on dried HAp and 5AlHAp 
Table 1. Physico-chemical characteristics and experimental phenol sorption capacity of the wAlHAp composites. Initial concentration of $20 \mathrm{mg} / \mathrm{L}$, adsorbent dose of $2 \mathrm{~g} / \mathrm{L}, \mathrm{pH} 5.6$ at room temperature.

\begin{tabular}{llllllll}
\hline & $\mathrm{Ca} / \mathrm{P}$ & $\% \mathrm{Al}$ & $\mathrm{S}_{\mathrm{BET}}$ & $\begin{array}{l}\mathrm{D}_{\mathrm{p}} \\
(\mathrm{nm})\end{array}$ & \multicolumn{3}{c}{$\begin{array}{c}\text { Adsorption } \\
\left(\mathrm{mg} \mathrm{g}^{-1}\right) \\
2-\end{array}$} \\
& & & $\left(\mathrm{m}^{2} / \mathrm{g}\right)$ & & $\mathrm{Ph}$ & $2-$ \\
& & & & & & $\mathrm{CPh}$ & $\mathrm{NPh}$ \\
\hline HAp & 1.95 & - & 100 & 12.4 & 2.95 & 9.36 & 5.06 \\
5AlHAp & 1.70 & 2.59 & 206 & $3.7 ; 8.4$ & 5.57 & 9.65 & 5.40 \\
10AlHAp & 1.72 & 4.44 & 152 & $3.8 ; 9.5$ & 6.70 & 9.59 & 5.33 \\
\hline
\end{tabular}

Results show that 2-chlorophenol is more retained than that of 2-nitrophenol and phenol. This behavior can attribute the difference to the chemical structure of phenols, i.e. the high electronegativity of chlorine affects the $\pi-\pi$ delocalization of electrons, weakening the $\mathrm{OH}$ bond of phenol to make $\mathrm{C}_{6} \mathrm{H}_{6} \mathrm{O}^{-}$more attractive for positive charges, $\mathrm{Ca}^{2+}$ and $\mathrm{Al}^{3+}$, on composite surfaces. Then, the electron density in the $\pi$-system of $\mathrm{C}_{6} \mathrm{H}_{6}$ - ring is reduced related to acceptor mechanism of the 2-chloro group in 2-nitrophenol in comparison to phenol itself. The regeneration on the adsorption capacity of 5AlHAp and HAp materials was studied by the heat treatment of the different adsorbents at $500^{\circ} \mathrm{C}$ for 3 hours of calcination after adsorption with initial concentration of $20 \mathrm{mg} / \mathrm{l}$ of the phenols at $\mathrm{pH}$ 5. A re-absorption of phenolic compounds under the same operating conditions was carried out on the adsorbents regenerated after three cycles of sorption. Within $20 \mathrm{mg} / \mathrm{L}$ as initial concentration, a very slight reduction of adsorption capacities, $5 \%$ for three tests, were obtained compared to those obtained before regeneration (a reduction of 2-3\% for each test)

\section{Conclusion}

This study developed the effective adsorbents for water treatment contaminated with phenol (Ph), 2chlorophenol (2-CPh) and 2-nitrophenol (2-NPh). The results indicated that 2-chlorophenol is more adsorbed on HAp and wAlHAP composites compared to Phenol and 2-nitrophenol in order 2-CPh> 2-NPh> $\mathrm{Ph}$. The efficiency of 10AlHAp was higher than that of the other adsorbents for the three phenolic compounds. The studied eco-friendly composites resulting from a soft chemistry approach with low-cost natural phosphate show promising properties in terms of surface affinity for phenol and its derivatives.

\section{References}

[1] A. Maleki, A.H. Mahvi, A. Mesdaghinia, K. Naddafi, Bull. Chem. Soc. Ethiop. 21, 2007, 33-38.

[2] A.H. Mahvi, A. Maleki, M. Alimohamadi, A. Ghasri, Kor.J.Chem.Eng. 24, 2007, 79-82.

[3] A. Adak, A. Pal, M. Bandyopadhyay, Colloids Surf. A 277, 2006, 63-68.

[4] A. Gholizadeh, M.Kermani, M. Gholami, M.Farazadkia, K. Yaghmaeian, Asian J Chem. 25, 2013, 3871-3878.

[5] V.C. Srivastava, M.M. Swamy, I.D. Mall, B. Prasad, I.M. Mishra, Colloids Surf A, 272, 2006, 89-104.

[6] H.Bouyarmane, S. El Asri, A.Rami, C.Roux, M.A. Mahly, A.Saoiabi, A. Laghzizil, J.Hazard. Mater. 181, 2010, 736-741.

[7] X. Wang, Clean-Soil, Air, Water, 39, 2011, 13-20
[8] H. Bouyarmane, S. Saoiabi, I. El Hanbali1, M. El Karbane, A. Rami, S. Masse, A. Laghzizil, T. Coradin, Eur. Phys. J. Special Topics 224, 2015, 1863-1871

[9] S. El Asri, A. Laghzizil, T. Coradin, A. Saoiabi, A. Alaoui, R. M'hamed, Colloids and Surfaces A, 362, 2010, 33-38.

[10] K. Achelhi, S.Masse, G.Laurent, C. Roux, A. Laghzizil, A. Saoiabi, and T. Coradin, Langmuir 27, 2011, 15176-84.

[11] T. D.Pham, T. T.Tran, V. A.Le, T. T. Pham, T. H. Dao, T. S.Le, J. Molecular Liquids, 287, 2019, 110900,

[12] T. G. Danis, T. A. Albanis, D. E. Petrakis, P. J. Pomonis, Water Research 32, 1998, 295-302

[13] K. Bouiahya, I.Es-saidi, A.Laghzizil,, D.Robert, J.M.Nunzi, A.Saoiabi, Colloid and Interface Science Communications 31, 2019, 100188.

[14] S. El Asri, A. Laghzizil, T. Coradin, A. Saoiabi, A. Alaoui, R. M'hamed Colloids and Surfaces A, 362 (2010) 3338.

[15] N.S. Abuzaid, G.F. Nakhla, Effects of solution pH on the kinetics of phenolics uptake on granular activated carbon, J. Hazard. Mater. 49 (1996) 217-230. 